\title{
Hominoid triosephosphate isomerase: Regulation of expression of the proliferation specific isozyme
}

\author{
Susan E. Old ${ }^{1}$, Laurie E. Landa and Harvey W. Mohrenweiser ${ }^{2}$ \\ Department of Human Genetics, University of Michigan Medical School, Ann Arbor, MI 48109-0618, USA; \\ current address: ' NIH/NEI/LMOD, Bldg 6 Room 231, 9000 Rockville Pike, Bethesda, MD 20892, USA; \\ ${ }^{2}$ Biomedical Sciences Division, L-452, Lawrence Livermore National Laboratory, Livermore, \\ CA 94550, US.A
}

Received 23 June 1988; accepted 6 February 1989

Key words: triosephosphate isomerase, cell proliferation, isozymes, mRNA, primate, human

\section{Summary}

Three primary isoforms of the dimeric glycolytic enzyme, triosephosphate isomerase (TPI; EC 5.3.1.1), are detected in proliferating human cells. The electrophoretically separable isoforms result from the three possible combinations of constitutive subunits and subunits expressed only in proliferating cells. Only a single primary isoform is observed in quiescent cells. The two subunits, which differ by covalent modification (s), are products of the single structural locus for this enzyme. Expression of the proliferation specific subunit (TPI-2) is detected within 6-10 hr following mitogen stimulation of quiescent human cells, requires RNA synthesis and is inhibited by agents which inhibit interleukin 2 expression or function. Only the constitutive subunit (TPI-1) is detected in proliferating cells from nonhominoid primate species. A single class of TPI mRNA, which is increased $>10$ fold following stimulation of quiescent cells, is detected on northern blot analysis and S1 nuclease digestion analysis of RNA from quiescent and proliferating human cells. It is similar in size to the TPI mRNA from proliferating cells of the African green monkey, a primate species not expressing TPI-2. Comparison of the structure of the TPI gene from rhesus monkey (nonexpressing species) to the gene from expressing species does not suggest a mechanism for generating TPI-2. Thus, the regulation of the expression of the hominoid restricted, proliferation specific subunit of TPI has been further defined, although the mechanism for generating TPI-2 remains elusive.

\section{Introduction}

Cells, as they progress through the cell cycle, express specific genes including oncogenes [1-5], growth factors $[6,7]$ and several enzymes and other gene products [8-14]. Some of these variably expressed genes, such as the oncogenes and growth factors, are believed to have a direct role in the regulation of cellular proliferation, while other gene products have a role in sustaining the cellular functions necessary for competence, progression and cell division. Definition of the regulation as well as the mechanism(s) of variable gene expression is crucial to understanding cellular growth and proliferation.

Triosephosphate isomerase (TPI; EC 5.3.1.1) exhibits a unique cell cycle dependent expression. This enzyme is a dimeric, glycolytic enzyme with a high catalytic efficiency [15] and a very slow rate of evolution [16]. It is a prevalent protein, present in 
all cells examined from a wide range of species $[17$, 18]. TPI activity increases when mammalian cells are stimulated to proliferate and in proliferating hominoid cells, a second, electrophoretically-distinct subunit of TPI (TPI-2) is synthesized [13, 1922]. Genetic evidence demonstrates that TPI-2 is a product of the same structural locus as the constitutive subunit, TPI-1 [19, 23]. This is consistent with the molecular data that indicates the existence of only a single functional TPI locus and that it is located on human chromosome 12 [24]. Three possible combinations of primary subunits, TPI-1/1, TPI-1/2 and TPI-2/2, are observed in proliferating cells; the level of the TPI $2 / 2$ isozyme consitutes less than $5 \%$ of the total TPI activity and therefore is difficult to detect, even in very rapidly dividing cells. The subunits have similar molecular weights, but the TPI-2 subunit is more acidic (covalent modification of $\sim 4$ charge units) and more thermolabile than TPI-1 $[19,25]$. The expression of TPI-2 is not a post-translational event [20] and requires both RNA and protein synthesis [21]. The expression of TPI-2 is seemingly unique among examples of expression of alternative isozymes or isoforms in that the second subunit is expressed only in proliferating cells and only in the cells of hominoid species $[17,26]$. Thus TPI, a constitutively expressed housekeeping enzyme exhibiting unique proliferation specific expression, provides an interesting system for the study of the regulation of gene expression.

We have examined TPI-2 appearance, as well as the increase in TPI mRNA and total TPI enzyme activity, in mitogen stimulated human peripheral lymphocytes and growth arrested human fibroblasts. Selected cell cycle inhibitors were used to further define the signals for and timing of the appearance of TPI-2.

\section{Methods}

\section{Cell culture - fibroblasts}

The human diploid dermal fibroblast line, GM10, (12 fetal weeks) was obtained from Dr. J. Thoene (Dept. of Pediatrics, Univ. of Michigan) and main- tained in RPMI 1640 (Gibco, Chagrin Falls, OH) supplemented with $10 \%$ fetal calf serum (Gibco), 50 units $/ \mathrm{ml}$ penicillin plus $50 \mu \mathrm{g} / \mathrm{ml}$ streptomycin (Gibco) and $2 \mathrm{mM}$ glutamine (Sigma, St. Louis, MO). Cells were split $1: 3$ at confluency $(0.25 \%$ trypsin (Sigma) in phosphate buffered saline (PBS)) into $75 \mathrm{~cm}^{2}$ culture flasks. Fibroblast cells were growth arrested by 11 days of incubation in media containing $0.25 \%$ fetal calf serum. This time period of incubation was necessary for the reduction of the TPI activity because of the 28-30 hour half life of TPI [20]. Cells were re-stimulated with $20 \%$ fetal calf serum, with or without various inhibitors [dexamethasone (DEX, 0.1 mM, Sigma), hydroxyurea (HU, $1 \mathrm{mM}$, Sigma), and 5-fluorouridine (FU, 0.2 mM, Calbiochem, San Diego, CA)] for indicated times, harvested, washed with PBS, and stored as pellets at $-70^{\circ} \mathrm{C}$.

\section{Cell culture - lymphocytes}

One unit of whole blood was collected from volunteer donors into ACD anticoagulant. The blood was centrifuged at $2000 \mathrm{rpm}$ for 10 minutes at room temperature. The buffy coat was removed, diluted with PBS supplemented with $0.1 \%$ glucose, layered over Histopaque-1077 (Sigma), and centrifuged at $1400 \mathrm{rpm}$ for 30 minutes at room temperature. The isolated lymphocytes were washed in mitogen-free media (RPMI 1640, 20\% fetal calf serum, 50 units $/ \mathrm{ml}$ penicillin plus $50 \mu \mathrm{g} / \mathrm{ml}$ streptomycin and $2 \mathrm{mM}$ glutamine) and counted. Cell recovery was $1.4 \pm 0.5 \times 10^{6}$ cells per $\mathrm{ml}$ whole blood.

Lymphocytes were seeded at $1-2 \times 10^{6}$ cells $/ \mathrm{ml}$ into the above media containing $20 \mathrm{mg} / \mathrm{ml}$ phytohemagglutinin-M (PHA, Difco, Detroit, MI) and/or $20 \mathrm{ng} / \mathrm{ml}$ phorbol 12-myristate 13-acetate (TPA, Sigma). Cells were stimulated/inhibited for indicated times, harvested, washed with PBS, and stored as pellets at $-70^{\circ} \mathrm{C}$.

\section{Protein/enzyme determinations}

Cell extracts were obtained by freeze/thawing as 
described by Decker and Mohrenweiser [19]. The supernatants were stored at $-70^{\circ} \mathrm{C}$. Total protein was determined using the BioRad Protein Assay Kit [27]. TPI, lactate dehydrogenase (LDH, E.C. 1.1.1.27), and glucosephosphate isomerase (GPI, E.C. 5.3.1.9) enzyme activities were determined as described by Fielek and Mohrenweiser [28]. Units of activity are $\mu \mathrm{mol}$ of product formed per minute. The relative distribution of the activity in the TPI $1 / 1$ and TPI $1 / 2$ isozymes was assessed by staining native polyacrylamide gels as described by Decker and Mohrenweiser [17]. Approximately equal units of total TPI activity were routinely loaded in each lane of the gells. Each gel was stained for several time periods to ensure that the relative staining intensity of each isozyme was a measure of relative differences in enzyme activity.

\section{RNA determinations}

RNA was extracted from frozen cell pellets of peripheral human lymphocytes, PHA stimulated human lymphocytes, human lymphoblasts, human fibroblasts and African green monkey kidney fibroblasts (vero, from M. Levine, Department of Human Genetics, University of Michigan) in guanidinium isothiocyanate as described by Manitias et al. [29]. RNA concentration was determined by spectrophotometric measurements.

Total glyoxal treated RNA [30] was used for both dot blot and northern blot analyses. Total RNA was electrophoretically separated and then transferred to GeneScreenPlus as recommended by Du Pont New England Nuclear (Boston, MA). The northern and dot blots were hybridized with a nick translated human TPI cDNA probe (pHTP15a) [31], a gift of Dr. L. Maquat, Dept. of Human Genetics, Roswell Park Memorial Institute, Buffalo, New York.

\section{S1 nuclease experiment}

A probe was constructed from the human TPI cDNA clone. The 936 bp EcoRI fragment corresponding to the entire TPI coding region (718 bp), except for $32 \mathrm{bp}$ of the $3^{\prime}$ end of the coding region and including 218 bp of the pKT 218 vector (see Fig. 2 of reference 31 for a detailed restriction site map of the cDNA) was the probe. This probe extends into exon 7 (the most $3^{\prime}$ exon) of the gene, thus it covers all of the known intron/exon junctions of the human gene [24]. The fragment was isolated from low melting point agarose (BRL) by melting the agarose at $60^{\circ} \mathrm{C}$ and then extracting the sample several times with an equal volume of phenol followed by ethanol precipitation.

The EcoRI fragment was dephosphorylated with calf intestinal alkaline phosphatase (BRL), then labeled using T4 polynucleotide kinase (BRL) and g- ${ }^{32}$ P-ATP (Amersham, Arlington Heights, IL). This labeled fragment was hybridized to $10 \mu \mathrm{g}$ of each of various total RNA samples at $57^{\circ} \mathrm{C}$ overnight in $80 \%$ formamide. The duplex was then digested with S1 nuclease (Promega) as described by Weaver and Weissman [32]. Briefly, 30 units of S1 nuclease was added to the DNA - RNA hybridization mix and incubated for 30 minutes at $37^{\circ} \mathrm{C}$. Nucleic acids were precipitated from the hybridization mixture, resuspended in $80 \%$ formamide, denatured $\left(3\right.$ minutes at $90^{\circ} \mathrm{C}$ ) and separated on a denaturing (6M urea) $6 \%$ polyacrylamide gel (1500 volts for 3-8 hours). After electrophoresis, an autoradiogram of the gel was made by an overnight exposure at $-70^{\circ} \mathrm{C}$.

\section{Results}

\section{Time course of TPI-2 appearance}

The time course of appearance of TPI- 2 and the role of several cellular growth factors in regulating TPI-2 activity were studied in human fibroblasts. An erythrocyte hemolysate and lysates from proliferating human lymphyblastoid cells and African green monkey kidney fibroblasts were routinely included as reference samples in each isozyme analysis. Two differences in the isozyme pattern are noteworthy in comparing the human samples in lanes 1 and 5 of Fig. 1. The four additional bands of TPI activity migrating immediately anodal of the primary TPI $1 / 1$ isozyme band in the erythrocyte 


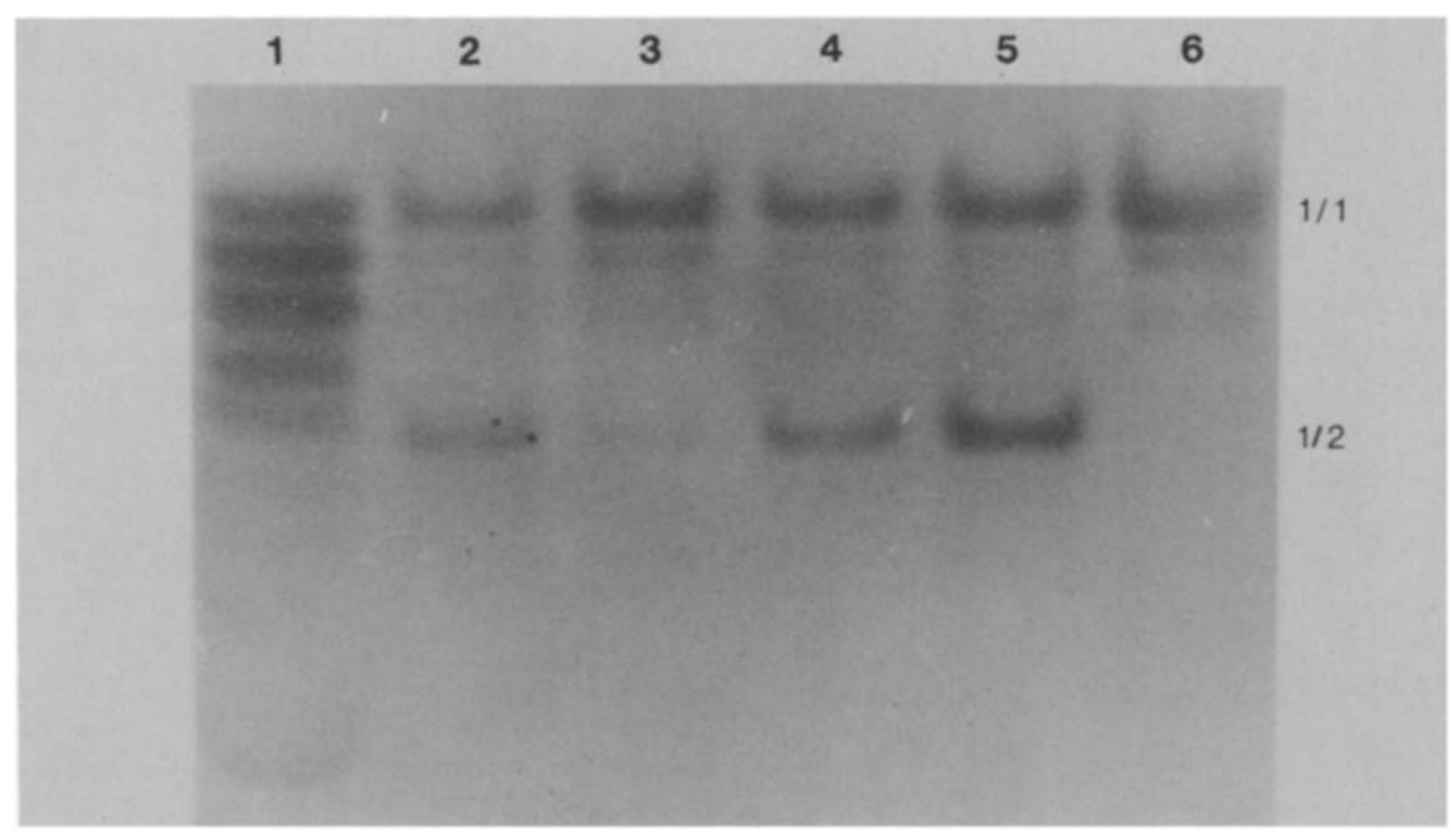

Fig. 1. Time course of TPI-2 appearance following serum stimulation of human fibroblasts. Human fibroblasts were rendered quiescent by serum deprivation for 11 days. The fibroblasts were restimulated by the addition of serum. Cell extracts were electrophoresed on a native polyacrylamide gel, which was then stained for TPI activity. Lane 1 - erythrocyte hemolysate standard, lane 2 - log phase human fibroblasts, lane 3 - human fibroblasts following 11 days of serum deprivation, lane 4 - serum restimulated quiescent human fibroblasts (24hr), lane 5 - human lymphoblast, lane 6 - vero fibroblast.

sample are the isozyme forms generated via the spontaneous deamidation of the two labile asparagine residues in each subunit [33]. Only the first of the deamidation products is marginally detectible

Table 1. Enzyme activity in serum deprived human fibroblasts

\begin{tabular}{|c|c|c|c|}
\hline \multirow[t]{2}{*}{ Days in $0.25 \%$ FCS } & \multicolumn{3}{|c|}{ Activity $^{\mathrm{a}}$} \\
\hline & TPI & $\mathrm{LDH}$ & GPI \\
\hline 0 & 1.964 & 0.035 & 0.010 \\
\hline 5 & 1.342 & 0.016 & 0.006 \\
\hline 11 & 0.652 & 0.008 & 0.003 \\
\hline $10 \mathrm{hrs}$ in $20 \% \mathrm{FCS}^{\mathrm{b}}$ & 0.960 & 0.017 & 0.006 \\
\hline $48 \mathrm{hrs}$ in $20 \% \mathrm{FCS}^{\mathrm{b}}$ & 1.510 & 0.021 & 0.008 \\
\hline
\end{tabular}

${ }^{a} \mu \mathrm{mol}$ product formed $/ \mathrm{min} / 10^{7}$ cells.

${ }^{\mathrm{b}}$ Cells had been grown in $0.25 \%$ FCS for 11 days before the addition of fresh media containing $20 \%$ FCS. FCS $=$ Fetal Calf Serum; TPI = Triosephosphate Isomerase; $\mathbf{L D H}=$ Lactate Dehydrogenase; GPI = Glucosephosphate Isomerase. in the proliferating lymphoblast sample. The second observation is the existence of a prominent isozyme (designated TPI 1/2) in the lymphoblastoid cell sample that does not comigrate with any of the isozyme forms of the erythrocyte sample. An additional, more anodal migrating isozyme can be detected in human lymphoblastoid cell samples if the staining time is increased (see Fig. 1 of reference 17). The isozyme ratio (TPI $1 / 1$ to TPI $1 / 2$ ) shifted during the period necessary for the cells to reach quiescence, with most of the residual activity associated with the TPI 1/1 isozyme in confluent fibroblasts maintained in $0.25 \%$ FCS for 11 days (lanes 2 and 3 ). The deamidated forms of the enzyme are also more prominent in the lysate from the quiescent cells. The level of total TPI activity was reduced to $30 \%$ of the initial activity during this interval (Table 1). As both TPI-1 and TPI-2 have the same rates of degradation [20], the change in isozyme profile reflects the continued synthesis of TPI-1, while TPI-2 synthesis was 'turned off' dur- 
A
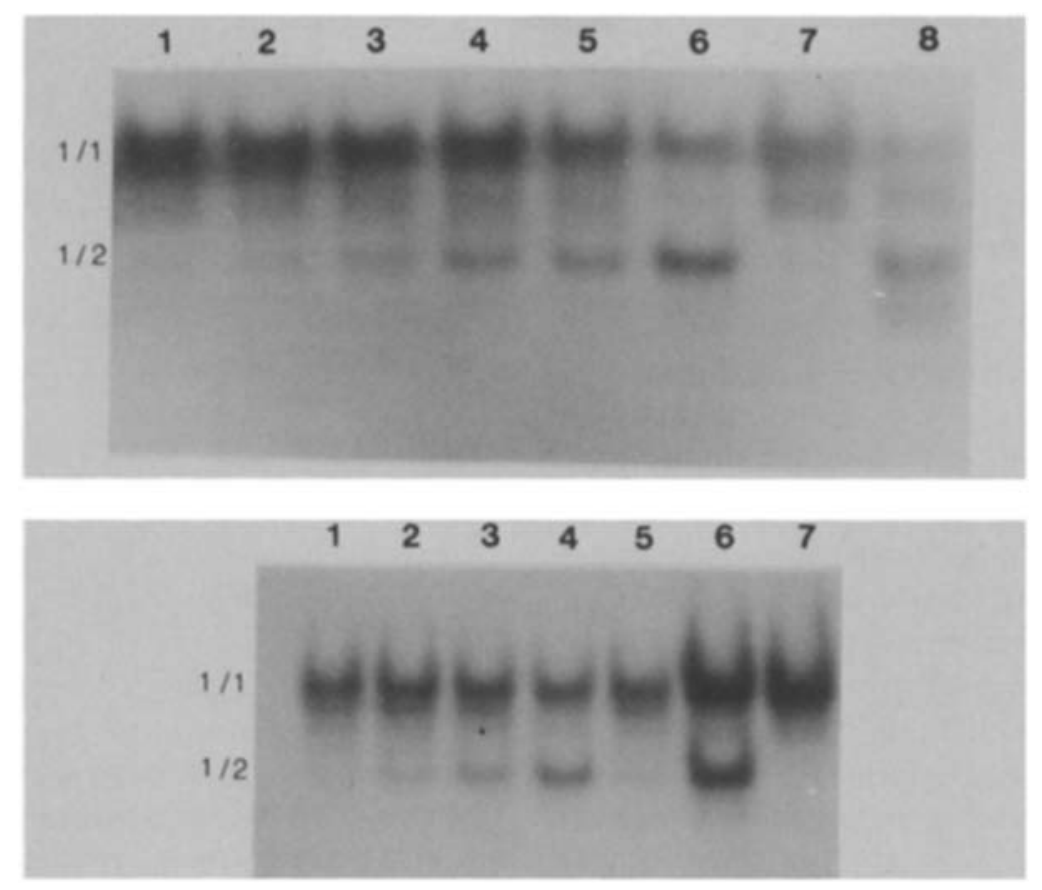

Fig. 2. Time course of TPI-2 appearance in stimulated lymphocytes. Peripheral human lymphocytes were stimulated with phytohemagglutinin (PHA). Cell extracts were electrophoresed through a non-denaturing gel and the gel was stained for TPI activity. A. Lane 1 - erythrocyte hemolysate standard, lane 2-0 hours after PHA addition, lane 3-6 hours after PHA addition, lane 4-12 hours after PHA addition, lane 5-24 hours after PHA addition, lane 6- 66 hours after PHA addition, lane 7 - vero fibroblast, lane 8 - human lymphoblast, B. Lane 1-0 hours after PHA addition, lane 2-12 hours after PHA addition, lane 3-24 hours after PHA addition, lane 4 48 hours aftêr PHA addition, lane 5-48 hours unstimulated, lane 6 - human lymphoblast, lane 7 - vero fibroblast.

TPI-1, while TPI-2 synthesis was 'turned off' during this time period. Stimulation of the quiescent fibroblasts by the addition of medium containing $20 \%$ FCS resulted in a two to three fold increase in total TPI activity (Table 1) and increased prominence of the TPI 1/2 isozyme within 24 hours (Fig. 1 , lanes 3 and 4 ). No indication of a proliferation specific isozyme is observed in proliferating fibroblasts from the African green monkey (vero) (lane $6)$.

Purified growth factors have been reported to stimulate an increase in TPI activity in quiescent rat cells [34]. A $50-80 \%$ increase in TPI activity was observed when quiescent human fibroblast cells were stimulated with fibroblast growth factor (FGF) or epidermal growth factor (EGF) (data not shown), while, as noted above, the TPI activity was increased 2.5 times at 24 hours and 3 -fold at 48 hours following stimulation with FCS. Thus, FGF and EGF were much less effective than $20 \%$ FCS in stimulating the increase in TPI activity in serum deprived human fibroblasts. The FGF and EGF stimulated increase in TPI activity was also associated primarily with the TPI-2 subunit.

TPI-2 activity was detectable by 6 hours and constituted a significant portion of the total TPI activity by 18 hours following PHA stimulation of human peripheral lymphocytes (Fig. 2). Equal amounts of total TPI activity were loaded in each lane in Fig. 2, thus, the apparent decline of the TPI $1 / 1$ isozyme reflects TPI- 2 synthesis and the increased contribution of TPI- 2 to the total TPI activity rather than a decrease in the TPI $1 / 1$ activity. The ratio of the activity associated with the TPI heterodimer (TPI 1/2) to the TPI 1/1 homodimer following 48 hours of PHA stimulation of lymphocytes (Fig. 2b lane 4) was approximately $1: 1$. This was similar to the relative distribution of the two 
isoforms observed in a rapidly dividing human lymphoblast cell line (TK6) (Fig. 2b lane 6 or lane 5 of Fig. 1). TPI 1/2 was barely visible in lymphocytes after 48 hours in RPMI media supplemented with FCS, but without the addition of mitogen (Fig. 2b lane 5). The isozyme distribution in these cells was similar to that observed at the initiation of the incubation (Fig. 2b lane 1).

Increased TPI activity, expressed on a per cell basis, was detected at 6-8 hours after initiation of stimulation and continued to increase for the duration of the experiment (Table 2), attaining a level three to four fold over TPI activity in non-stimulated lymphocytes. The basal level of activity in nonstimulated cells was approximately $5 \times 10^{-7}$ units/ cell. TPI activity increased to $18 \times 10^{-7}$ units/cell at 48 hours after PHA addition. While TPI enzyme activity per cell increased during this time, enzyme activity per $\mu \mathrm{g}$ of total cellular protein remained relatively constant after an initial increase occuring within the first $6-8$ hours of mitogen stimulation. Thus, the increase in TPI activity was similar to the increase of total protein observed in these cells. The changes in GPI and LDH enzyme activities followed the same pattern as TPI activity; they began to increase 6-8 hours after PHA addition and continued to increase through the remainder of

Table 2. Enzyme activity in mitogen stimulated peripheral lymphocytes

\begin{tabular}{rrrrr}
\hline Hours $^{\mathrm{b}}$ & \multicolumn{2}{l}{ Activity $^{\mathrm{a}}$} & & $\begin{array}{l}\text { Total } \\
\text { protein } \\
\mu \mathrm{g} / 10^{7} \\
\text { cells }\end{array}$ \\
\cline { 2 - 5 } & TPI & LDH & GPI & \begin{tabular}{l}
20.81 \\
\hline 0
\end{tabular} \\
\hline 6 & 5.2 & 0.05 & 0.49 & 74.15 \\
12 & 14.8 & 0.52 & 1.60 & 61.26 \\
18 & 10.7 & 0.52 & 1.41 & 64.25 \\
22 & 12.9 & 0.61 & 1.25 & 67.64 \\
26 & 11.2 & 0.70 & 1.27 & 78.11 \\
30 & 12.5 & 0.94 & 1.52 & 80.31 \\
36 & 14.0 & 1.24 & 1.61 & 72.17 \\
48 & 12.9 & 1.06 & 1.34 & 114.32 \\
\hline
\end{tabular}

${ }^{a} \mu$ mol product formed $/ \mathrm{min} / 10^{7}$ cells.

${ }^{\mathrm{b}}$ hours following addition of phytohemaggutinin $\mathrm{M}$. TPI = Triosephosphate Isomerase; LDH = Lactate Dehydrogenase; $\mathrm{GPI}=$ Glucosephosphate Isomerase. the experiment. This increased LDH activity was associated with a change from predominantly the muscle type (LDHA) isozyme to predominantly the heart type (LDHB) isozyme (not shown). The phorbol ester, phorbol 12-myristate 13-acetate, either alone or in combination with PHA did not stimulate TPI-2 accumulation or the increase in TPI activity (data not shown).

\section{Inhibition studies}

The effects of agents that interfere with cell division at different stages of the cell cycle on the FCS stimulated accumulation of TPI activity in quiescent fibroblasts are presented in Table 3. The inhibitors were added concurrently with FCS. Dexamethasone had its most significant effect at 24 hours, inhibiting $90 \%$ of the FCS response; the activity was also reduced at 48 and 60 hours. Hydroxyurea did not significantly affect the increase in TPI activity at the 24 hour time point but did inhibit the expected accumulation at 60 hours, probably reflecting decreased metabolic activity in cells where cell division is inhibited. The inhibition of the increase in TPI was reflected in the absence of the expected increase in the TPI $1 / 2$ isozyme relative to the level of the TPI $1 / 1$ isozyme. Fluorouridine, which inhibits RNA synthesis [35] (DNA synthesis would be inhibited at longer in-

Table 3. Triosephosphate isomerase activity in stimulated human fibroblasts

\begin{tabular}{lll}
\hline Treatment & \multicolumn{2}{l}{ Activity $^{\mathrm{a}}$} \\
\cline { 2 - 3 } & & \\
\hline 24 hours $^{\mathrm{b}}$ & 60 hours $^{\mathrm{b}}$ \\
\hline $0.25 \%$ FCS & 0.570 & 0.560 \\
$20 \%$ FCS & 1.380 & 1.460 \\
$20 \%$ FCS + DEX & 0.720 & 1.000 \\
$20 \%$ FCS + HU & 1.420 & 1.140 \\
$20 \%$ FCS + FU & 0.770 & 0.660 \\
\hline
\end{tabular}

${ }^{a} \mu$ mol product formed $/ \mathrm{min} / 10^{7}$ cells.

${ }^{\mathrm{b}}$ Hours after addition of $20 \%$ FCS following 12 days of $0.25 \%$ FCS. $F C S=$ Fetal Calf Serum; PHA $=$ Phytohemagglutinin-M; DEX $=$ Dexamethasone; $\mathrm{HU}=$ Hydroxyurea; $\mathrm{FU}=$ 5-fluorouridine. 
A
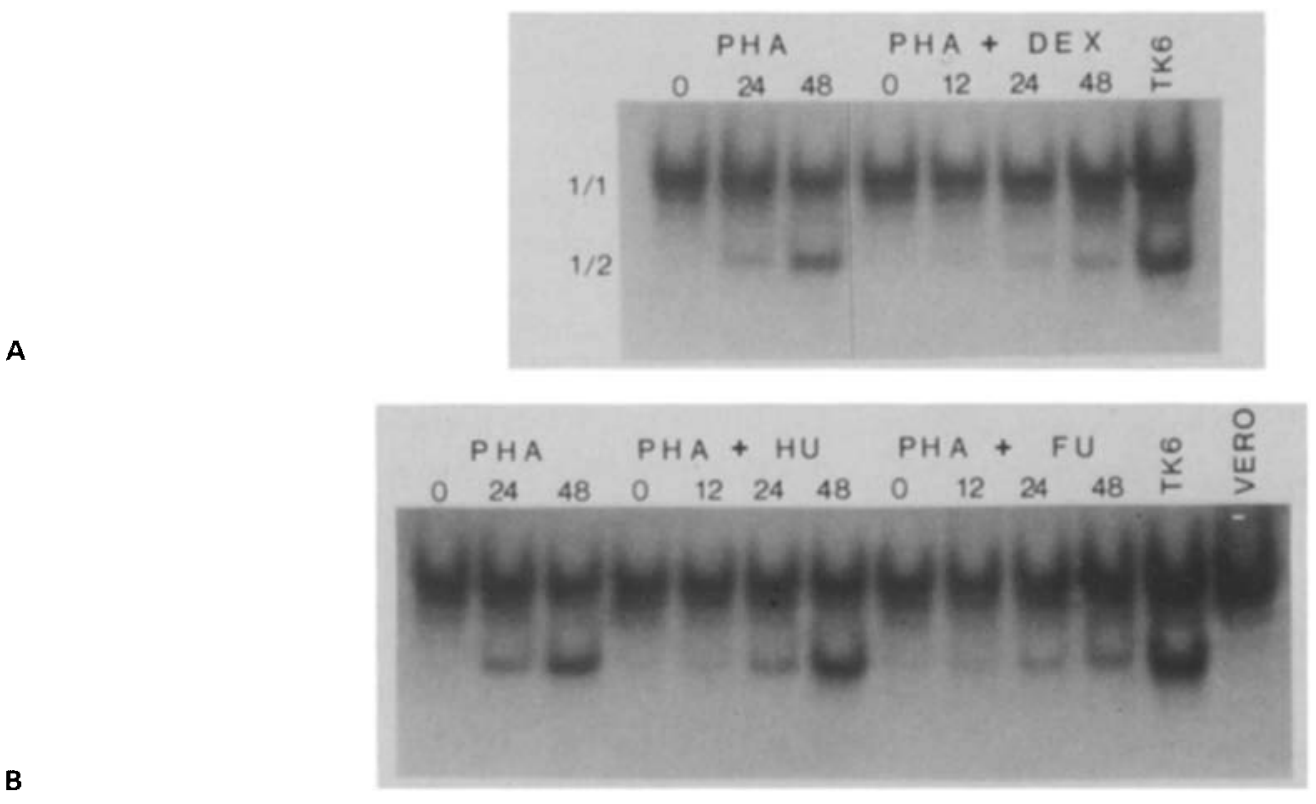

Fig. 3. Effects of inhibitors on TPI accumulation following mitogen stimulation of human lymphocytes. Peripheral lymphocytes were stimulated with phytohemagglutinin (PHA) 2.5 hours following addition of the inhibitor. Cells were harvested 0, 12, 24, or 48 hours after PHA stimulation. Cell extracts were electrophoresed on a native polyacrylamide gel, which was then stained for TPI activity. Abbreviations: $\mathrm{PHA}=$ Phytohemagglutinin-M, DEX $=$ Dexamethasone, $\mathrm{HU}=$ Hydroxyurea, $\mathrm{FU}=5$-Fluorouridine, $\mathrm{TK} 6=$ human lymphoblast, Vero $=$ African green monkey fibroblast.

cubation times), inhibited $>80 \%$ of the expected response to FCS. The incomplete effectiveness of FU reflects the time necessary for equilibration with the cellular uridine pool [36].

The effects of the inhibitors on TPI activity and TPI-2 appearance in stimulated lymphocytes were similar to the results observed in the fibroblast experiments. TPI activity increased 2.5 -fold by 12 hours following mitogen addition and remained constant throughout the remainder of the time course in this experiment. Treatment of lymphocytes with mitogen and dexamethasone prevented the increase in TPI activity observed with mitogen alone. At 48 hours following PHA addition, TPI activity in DEX plus PHA treated cells, was only $30 \%$ of the activity in PHA alone treated cells and the increase in TPI-2 activity observed following PHA stimulation was almost completely inhibited by DEX treatment (Fig. 3). In hydroxyurea plus PHA treated lymphocytes, TPI activity at 12 and 24 hours was $>70 \%$ of the level of activity in cells treated with PHA alone. The increase in TPI-2 activity was not diminished by the addition of $\mathrm{HU}$ to the mitogen stimulated cells (Fig. 3). Twelve hours following addition of PHA to fluorouridine treated cells, TPI activity was less than $50 \%$ that of PHA alone treated cells and was less than $30 \%$ of the activity in the mitogen cells at 48 hours. There was only a minimal appearance of TPI- 2 in FU plus PHA treated cells. The level of TPI- 2 in these cells was similar to the levels seen in cells with media alone (non-stimulated cells).

\section{TPI mRNA studies}

A single primary species of TPI mRNA was detected in human lymphocytes by northern blot analysis of RNA, although it is not possible to exclude the existence of additional mRNA species of similar size. This mRNA was approximately $1.2 \mathrm{~kb}$ in both dividing and non-dividing cells. This is the same size as previously reported [31] and is consistent with the size expected given the structure of the 


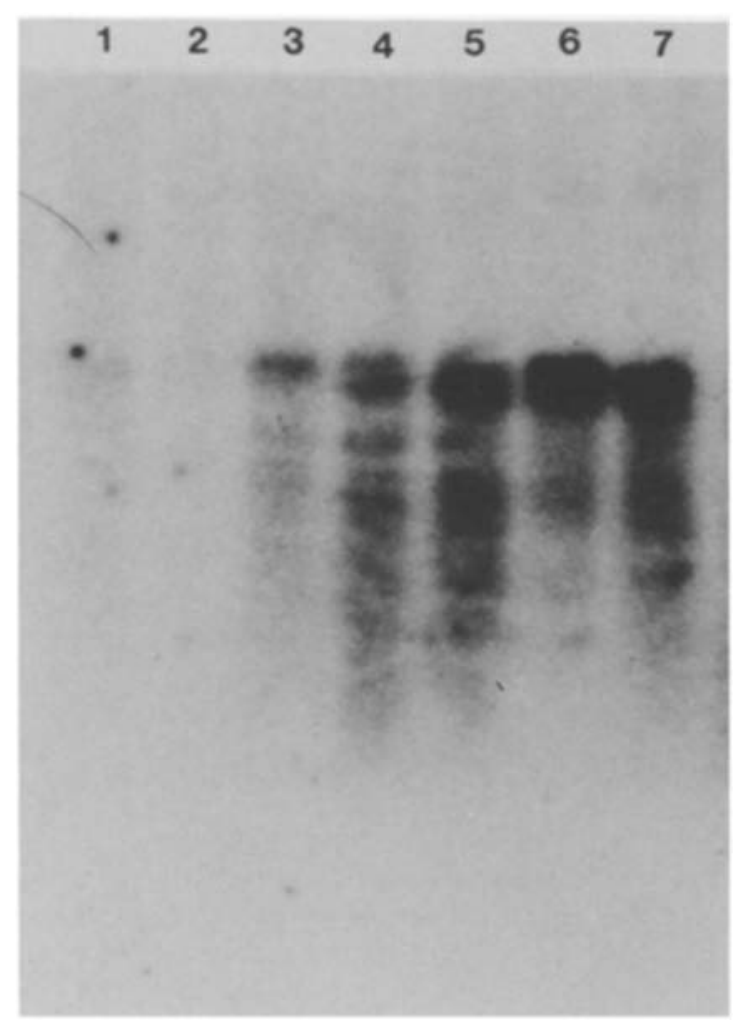

Fig. 4. TPI mRNA accumulation in mitogen stimulated lymphocytes. Total RNA was isolated from phytohemagglutinin (PHA) stimulated human lymphocytes. The RNA was treated with glyoxal, subjected to electrophoresis through a $1.1 \%$ agarose gel, transfered to GeneScreenPlus and hybridized with the human TPI cDNA probe. Shown is an overexposure of the autoradiogram. Lane $1-0$ hours after PHA addition, lane $2-4$ hours after PHA addition, lane $3-8$ hours after PHA addition, lane $4-12$ hours after PHA addition, lane 5-18 hours after PHA addition, lane 6-24 hours after PHA addition, lane 7-50 hours after PHA addition.

human [24] and rhesus genes [37]. TPI mRNA was barely detectable in RNA isolated from nondividing cells. Fig. 4 shows an overexposed autoradiograph, where the TPI mRNA in unstimulated cells ( 0 time, lane 1 ) can be visualized. The additional, smaller mRNAs are presumably partially degraded TPI mRNA molecules and are only observed upon the 4-5 fold overexposure of the autoradiograph necessary to detect a band in lane 1 . At 8 hours following PHA stimulation of lymphocytes (lane 3) the level of TPI mRNA has increased at least several fold. The TPI mRNA levels continue to increase, compared to total RNA, through the last time point in this experiment, which is 50 hours.

Only a single size TPI mRNA species was detectable in human fibroblasts and it is the same size as observed in lymphoblasts. The pattern for TPI mRNA appearance during serum deprivation and subsequent serum restimulation of human fibroblasts was similar to that observed for the TPI $1 / 2$ isozyme. The level of TPI mRNA in quiescent fibroblasts was significantly reduced relative to confluent cells and was almost undetectable in quiescent cells compared to the level in proliferating cells. At 20 hours following FCS stimulation, TPI mRNA was at least twice the level detected in confluent cells and more than 10 times the level in quiescent cells. The TPI mRNA returned to a level comparable to confluent cells at 36 and 52 hours following addition of FCS to quiescent fibroblasts. The cell growth factors, EGF and FGF, modulated TPI mRNA accumulation to an extent which was similar to the increase in TPI activity.

The various agents which inhibited the mitogen stimulated increase in TPI activity and the expression of TPI-2 also prevented the mitogen stimulated accumulation of TPI mRNA. Analysis of dot blots of total RNA from stimulated lymphocytes, probed for TPI mRNA, showed that the TPI mRNA level was less in cells treated with DEX plus PHA than in cells treated with PHA alone and was only slightly increased over that detected in unstimulated cells. HU plus PHA treatment did not significantly affect TPI mRNA levels but FU plus PHA drastically reduced TPI mRNA accumulation compared to TPI mRNA levels in cells treated with PHA alone. The pattern was exactly that observed for TPI 1/2 appearance.

DNA synthesis, as measured by $\left[{ }^{3} \mathrm{H}\right]$-thymidine incorporation into trichloroacetic acid precipitated material, began at 30-36 hours following mitogen stimulation (data now shown).

\section{S1 nuclease mapping}

An autoradiogram of the S1 nuclease digestion pattern obtained with the EcoRI fragment of the cDNA is seen in Fig. 5. The EcoRI probe hybrid- 

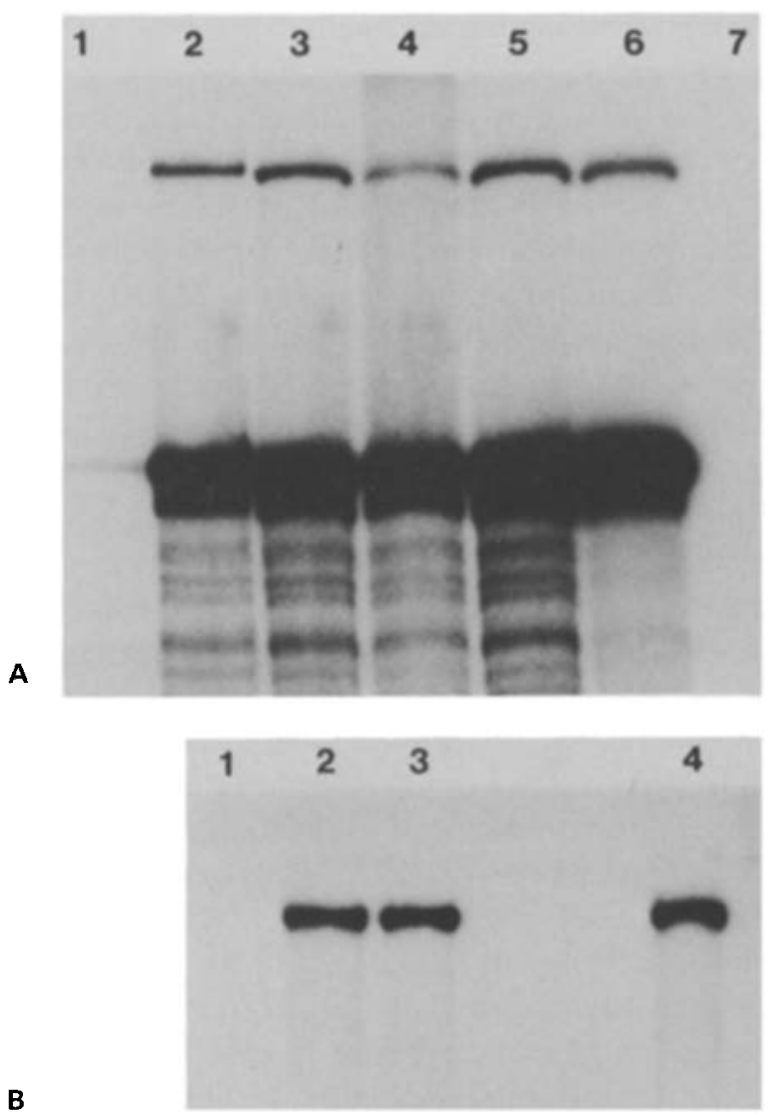

Fig. 5. S1 nuclease digestion analysis of TPI mRNA. Total RNA isolated from a series of cells was hybridized to the EcoRI probe, the non-hybridizing segments were digested with S1 nuclease and the samples electrophoresed as described in Methods. A. Lane 1 - unstimulated peripheral human lymphocytes, lanes 2 and 3 are 24 and 48 hours after PHA stimulation of peripheral human lymphocytes, lane 4 - human lymphoblasts, lane 5-human lymphoblasts from the TPI Manchester variant, lane 6-human lymphoblast, lane 7-no RNA control. B. Lane 1 - no RNA control, lane 2 - 48 hours after PHA stimulation of human lymphocytes, lane 3 - human lymphoblast, lane 4 - vero fibroblast. The dark band in each figure is the protected fragment of the EcoRI probe ( $718 \mathrm{bp})$.

izes with the entire coding region expected in the mature TPI mRNA, except for the 32 bases at the $3^{\prime}$ end of the coding sequence, which are lacking in this probe. In panel A, lanes 1,2 , and 3 correspond to $\mathrm{S} 1$ nuclease digestions of RNA isolated from peripheral human lymphocytes of the same individual at zero time (lane 1) and 24 hours (lane 2) or 48 hours (lane 3) after initiation of mitogen (PHA) stimulation. Panel A is an overexposure of the film (as compared to panel B) in order to detect the band in lane 1. As seen in panel B, the multiple minor bands are not observed without the overexposure. These minor bands are presumably associated with hybridization to partially degraded mRNAs and/or 'nibbling' by the nuclease. The level of TPI mRNA dramatically increased in stimulated cells as was observed by northern analysis of the cells from the time course study. However no primary bands were observed in the proliferating cells which were not also present in the mRNAs from cells prior to mitogen stimulation. Lanes 4, 5, and 6 are $\mathrm{S} 1$ digestions of RNAs isolated from several rapidly dividing transformed human lymphoblastoid cell lines, cells which express high levels of TPI-2. Fig. 5B lane 4 is the result of an S1 digestion of vero RNA hybridized with the human EcoRI cDNA fragment. The single protected fragment is the same size as is observed in RNA from human cells. These data would exclude significant differences in mRNA structure associated with differential mRNA splicing between proliferating and nonproliferating human cells and also between human and vero cells.

\section{Discussion}

The single structural locus for TPI located on human chromosome 12 [24] encodes two electrophoretically distinct peptides $[19,23]$. The expression of two subunits from a single gene for TPI is in contrast to several other glycolytic enzymes e.g. lactate dehydrogenase, aldolase and pyruvate kinase where the different primary isoforms arise from distinct genes in a gene family [38-40] although pyruvate kinase also expresses two isozymes from each of the structural loci [38]. The TPI-1 and TPI-2 peptides (subunits) differ by one or more covalent modifications involving approximately four charge units [20] which results in differences in thermostability $[19,21]$ but no-kinetic properties [25]. These structural differences responsible for the expression of the TPI-2 subunit are independent of the spontaneous deamidations of the labile asparagine residues $[17,20]$. The TPI-1 subunit is observed in a wide range of cells [18] 
while TPI-2 is only observed in proliferating cells $[19,21,22]$ derived from hominoid species (from human to gibbon) $[17,26]$. The proliferation specific, hominoid restricted subunit is detected in Chinese hamster ovary cells (which express only a constitutive hamster isozyme) which contain human chromosome 12 as the only human chromosome [41]. Thus, at least one of the critical pieces of information for the expression of the proliferation specific isozyme must be resident in the gene. That is, irrespective of the mechanism (alternative mRNA splice sites, amino acid residues which are potential substrates for modification, or some other mechanism) the primary transcript of the structural locus or subsequently the gene product must be the substrate for the modification.

The TPI-2 subunit of TPI was detectable within 6-10 hours following mitogen stimulation of human peripheral lymphocytes or serum restimulation of quiescent human fibroblasts. Total TPI activity increased 2.5 to 3.0-fold during the first 8-24 hours of stimulation with most of the increase associated with TPI-2. TPI-2 increased from almost undetectable levels ( $<5 \%$ of total activity) in quiescent peripheral lymphocytes to $30-35 \%$ of the total activity in lymphocytes stimulated for $24 \mathrm{hrs}$ with mitogen [20]. Only the constitutive TPI subunit was detectable in mitogen stimulated rabbit lymphocytes or proliferating fibroblasts from the African green monkey (Vero) or other lower primates $[17,26]$.

As previously noted [21], TPI-2 expression was dependent upon RNA synthesis. This would be consistent with the absence of a precursor-product relationship between the subunits [20], unless expression of TPI-2 was dependent upon de novo synthesis of an unidentified modifier enzyme which must also be located on human chromosome 12 to be consistent with the data from the human/hamster hybrid cell study. The expression of TPI-2 before DNA synthesis would be consistent with an absence of significant inhibition of TPI-2 expression by hydroxyurea, an agent which blocks DNA synthesis [42]. The absence of a requirement for DNA synthesis plus the observation that TPI-2 expression occurs concurrently with TPI-1 expression and is reversible argues against either gene duplication or rearrangement as a mechanism for TPI-2 expression.

The inhibition of the mitogen stimulated increase in total TPI activity and TPI-2 expression by DEX has several implications. DEX presumably acts by inhibiting interleukin-2 (IL-2) production or interleukin-2 receptor expression $[5,43]$. Thus, the increase in TPI activity and TPI-2 expression require early events in the $\mathrm{T}$-cell activation sequence which either involve IL- 2 or are induced by IL-2 [6]. Inhibition of TPI-2 expression by cyclosporin A (Mohrenweiser, unpublished) would be consistent with the requirement for interleukin-2 function [5, 7, 43]. Additionally, the inhibition of both TPI-2 expression and the increase in total TPI activity suggests that either these events are linked or that they are both responding to similar activation signals. The expression of TPI- 2 during cellular proliferation has characteristics that are similar to the expression of several oncogenes and growth factors $[3,44,45]$, except that TPI-2 results from apparently altered expression of an already active gene instead of expression of a previously inactive gene. It is noted that the apparent increase in TPI mRNA following stimulation of quiescent cells (approximately 10-fold or greater) is larger than the increase in total TPI activity ( $2-4$ fold) in either lymphocytes or fibroblasts.

Although the regulation of expression of TPI-2 must be associated with early events in the $G_{1}$ phase of cell proliferation [46], the mechanism for generating the second subunit from the single structural locus is still undefined. Previous data have eliminated a precursor-product relationship between the subunits [20] and the subunits do not differ significantly in molecular weight $[20,25]$. The requirement for de novo protein synthesis for expression of the TPI-2 subunit [21] would be consistent with the requirement for mRNA synthesis and also the absence of a precursor-product relationship between the subunits. The requirement for mRNA synthesis would seem to also exclude, with the exception of a mechanism involving a linked (on human chromosome 12) modifier enzyme, differential modification during nascent peptide synthesis. Additionally, neither subunit is phosphorylated $[47,48]$, thus differential phosphorylation does 
account for the charge difference and preliminary results indicate that neither subunit is sulfated [48].

A relatively common mechanism for generating two (or more) proteins from a single structural locus involves differential processing of the primary RNA transcript [49]. Many of these gene products exhibit tissue specific [50-53] and/or developmental stage specific [54-57] expression. Thus, differential splicing can be a regulated process. However, TPI-2 expression exhibits neither developmental nor tissue specificity. Rather, it is regulated by, or a product of, cellular proliferation, and its expression is restricted to hominoid species. Only a single size species of TPI mRNA was detected in either quiescent or proliferating cells and this mRNA was $1.2 \mathrm{~kb}$ in both TPI-2 expressing and nonexpressing cells. Similarly, only a single TPI mRNA species could be detected by $\mathrm{S} 1$ nuclease analysis of RNA isolated from proliferating human cells, and the protected fragments were the same size in both quiescent and proliferating cells using a probe that includes all of the known splice junctions and all but 32 nucleotides at the 3 ' end of the coding region of the cDNA [37]. Vero cells do not express the TPI-2 subunit, thus, if differential mRNA processing is the mechanism for generating the TPI-2 subunit, vero should also exhibit, along with the sample from quiescent cells, an S1 nuclease digestion pattern for TPI mRNA which is less complex than the pattern observed in the proliferating human lymphoblasts. This was not observed. Additional preliminary results with a probe that encompasses the $3^{\prime}$ untranslated portion of the gene and the $3^{\prime}$ half of the coding region, including 310 nucleotides that overlap the EcoRI fragment cDNA probe, provide no indication of the existence of different or multiple mRNA species in proliferating and nonproliferating human cells or differences in the mRNAs of human and vero cells in the region of the translation termination site or the 3' untranslated region (Old, unpublished observations). No evidence of an additional, alternative exon has been identified in either the sequence or restriction enzyme site map of the human [24] or rhesus [37] TPI genes.

The functional TPI genes from two primate species, rhesus (Macaca mulatta) which does not ex- press a TPI-2 subunit and chimpanzee (Pan troglodytes) which expresses TPI-2, have been recently cloned and sequenced ([37] L. Craig, pers. commun). The human gene has also been previously sequenced [24]. The nucleotide sequence of the coding regions of rhesus and chimpanzee TPI genes are $98 \%$ identical and between rhesus and human the identity in nucleotide sequence is $97 \%$. No amino acid differences are noted in comparing the derived enzyme sequences from chimp and human while the derived rhesus enzyme sequence differs from the chimp and human sequences by two residues. The enzyme from rhesus has an asparagine residue instead of a serine at position 20 and a glutamic acid at position 198 instead of an aspartic acid. Although the serine in the hominoid enzyme is a potential site for several different covalent modifications, two of these (phosphorylation and sulfation) have already been excluded. Additional$\mathrm{ly}$, the presence of the serine does not correlate with the species restricted expression as a serine residue exists at this position in the enzyme of several other species, including the chicken [58], which does not express a second isozyme [17].

Inspection of the chimp gene provides no evidence for the existence of additional exons which could be possible substrates for alternative processing and comparison of the nucleotide sequence of the gene from chimp and rhesus does not indicate sequences that would be suggestive of potential alternative splice sites in the chimp gene that are absent in the rhesus gene. These observations would be consistent with the absence of multiple mRNAs that are of sufficient difference to be detected by $\mathrm{S} 1$ nuclease mapping.

Thus, although further insight into the regulation of the expression of the hominoid restricted, proliferation specific isozyme of TPI is presented, the mechanism for generation of the TPI-2 subunit remains elusive.

\section{Acknowledgements}

The assistance of S. Fielek and H. Wurzinger as well as the guidance of S. Fretag is gratefully acknowledged. The cooperation of L. Craig and R. 
Pirtle in providing the sequence of the chimpanzee TPI gene is appreciated. This work was supported by the NIH Training Grant T32-GM07544 (SEO) and DOE contract AC-02-82ER60089.

\section{References}

1. Armelin HA, Armelin MCS, Kelly K, Stewart T, Leder P, Cochran BH, Stiles CD: Functional role for c-myc in mitogenic response to platelet-derived growth factor. Nature 310: 655-660, 1984

2. Greenberg ME, Ziff EB: Stimulation of $3 \mathrm{~T} 3$ cells induces transcription of the c-fos proto-oncogene. Nature 311: 433 438,1984

3. Kaczmarek L, Calabretta B, Baserga R: Expression of cell-cycle-dependent genes in phytohemagglutinin-stimulated human lymphocytes. Proc Natl Acad Sci USA 82: 5375-5379, 1985

3. Kelly K, Cochran BH, Stiles CD, Leder P: Cell-cycle specific regulation of the c-myc gene in lymphocytes by mitogens and platelet-derived growth factor. Cell 35: 603-610, 1983

5. Reed JC, Nowell PC, Hoover RG: Regulation of c-myc mRNA in normal human lymphocytes by modulators of cell proliferation. Proc Natl Acad Sci USA 82: 4221-4224, 1984

6. Efrat S, Kaempfer R: Control of biologically active interleukin-2 messenger RNA formation in induced human Iymphocytes. Proc Natl Acad Sci USA 81: 2601-2605, 1984

7. Elliott JF, Lin Y, Mizel SB, Bleackley RC, Harnish DG, Paetkau V: Induction of interleukin 2 messenger RNA inhibited by cyclosporin A. Science 266: 1439-1441, 1984

8. Liu HT, Gibson CW, Hirschhorn RR, Rittling S, Baserga R, Mercer WE: Expression of thymidine kinase and dihydrofolate redutase genes in mammalian ts mutants of the cell cycle. J Biol Chèm 260: 3269-3274, 1985

9. Johnson LF, Fuhrman CL, Wiedemann LM: Regulation of dihydrofolate reductase gene expression in mouse fibroblasts during transition from the resting to growing state. J Cell Physiol 97: 397-406, 1978

10. Kester MV, Phillips TL, Gracy RW: Changes in glycolytic enzyme levels and isozyme expression in human lymphocytes during blast transformation. Arch Biochem Biophys 183: 700-709, 1977b

11. Mach M, White MW, Neubauer M, Degen JL, Morris DR: Isolation of a cDNA clone encoding S-adenosylmethionine decarboxylase [Expression of a gene in mitogen-activated lymphocytes]. J Biol Chem 261: 11697-11703, 1986

12. Mariani BD, Slate DL, Schimke RT: S phase-specific synthesis of dihydrofolate reductase in Chinese hamster ovary cells. Proc Natl Acad Sci USA 78: 4985-4989, 1981

13. Rogers PA, Brenton DP, Hopkinson DA: Changes in the activity and isozyme patterns of glycolytic enzymes during stimulation of normal human lymphocytes with phytohaemagglutinin. Ann Hum Genet Lond 43: 213-226, 1980
14. Wiedemann LM, Johnson LF: Regulation of dihydrofolate reductase synthesis in an overproducing 3 T6 cell line during transition from resting to growing state. Proc Natl Acad Sci USA 76: 2818-2822, 1979

15. Albery WJ, Knowles JR: Evolution of enzyme function and the development of catalytic efficiency. Biochemistry 15 : 5631-5640, 1976

16. Marchionni M, Gilbert W: The triosephosphate isomerase gene from maize: introns antedate the plant-animal divergence. Cell 46: 133-141, 1986

17. Decker RS, Mohrenweiser HW: Cell proliferation-associated expression of a recently evolved isozyme of triosephosphate isomerase. Biochem Genet 23: 267-280, 1985

18. Snapka RM, Sawyer TH, Barton RA, Gracy RW: Comparison of the electrophoretic properties of triosephosphate isomerase of various tissues and species. Comp Biochem Physiol 49B733-741, 1974

19. Decker RS, Mohrenweiser HW: Origin of the triosephosphate isozymes in humans: Genetic evidence for the expression of a single structural locus. Am J Hum Genet 33: 683-691, 1981

20. Decker RS, Mohrenweiser HW: Hominoid triosephosphate isomerase: Characterization of the major cell proliferation specific isozyme. Mol Cell Biochem 71: 31-44, 1986

21. Kester MV, Jacobsen EL, Gracy RW: The synthesis of a labile trisephosphate isomerase isozyme in human lymphoblasts and fibroblasts. Arch Biochem Biophys 180: 562569,1977

22. Rubinson H, Vodovar M, Meienhofer MC, Dreyfus JC: A unique electrophoretic pattern of triosephosphate isomerase in human cultured fibroblasts. FEBS Lett 3: 290-292, 1971

23. Asakawa J, Iida I: Origin of human triosephosphate isomerase isozymes: Futher evidence for the single structural locus hypothesis with Japanese variants. Hum Genet 71: 22-26, 1985

24. Brown JR, Daar IO, Krug JR, Maquat LE: Characterization of the functional gene and several processed pseudogenes in the human triosephosphate isomerase gene family. Mol Cell Biol 5: 1694-1706, 1985

25. Yuan PM, Dewan RN, Zaun M, Thompson RE, Gracy RW: Isolation and characterization of triosephosphate isomerase isozymes from human placenta. Arch Biochem Biophys 198: 42-52, 1979

26. Rubinson $\mathrm{H}$, Meienhofer MC, Dreyfus JC: A new isozyme of triose phosphate isomerase specific to hominoids. J Mol Evol 2: 243-250, 1973

27. Sedmark JJ, Grossberg SE: A rapid, sensitive, and versatile assay for protein using coomassie brilliant blue $\mathbf{G} 250$. Anal Biochem 79: 544-552, 1977

28. Fielek S, Mohrenweiser HW: Erythrocyte enzyme deficiencies assessed with a miniature centrifugal analyzer. Clin Chem 25: 384-388, 1977

29. Maniatis T, Fritsch EF, Sambrook J: Molecular Cloning, A Laboratory Manual. Cold Spring Harbor Press, New York 1982 
30. Thomas PS: Hybridization of denatured RNA and small DNA fragments transferred to nitrocellulose. Proc Natl Acad Sci USA 77: 5201-5205, 1980

31. Maquat LE, Chilcote R, Ryan PM: Human triosephosphate isomerase cDNA and protein structure. J Biol Chem 260: 3748-3753, 1985

32. Weaver RF, Weissman C: Mapping of RNA by a modification of the Berk-Sharp procedure: the $5^{\prime}$ termini of $15 \mathrm{~S}$ b-globin mRNA precursor and mature 10S b-globin mRNA have identical map coordinates. Nucl Acids Res 7: 11751193, 1979

33. Yuan PM, Talent JM, Gracy RW: Molecular basis for the accumulation of acidic isozymes of triosephosphate isomerase on aging. Mech Aging Devel 17: 151-162, 1981

34. Matrisian LM, Rautmann G, Magun BE, Breathnach R: Epidermal growth factor or serum stimulation of rat fibroblasts induces an elevation in mRNA levels for lactate dehydrogenase and other glycolytic enzymes. Nucl Acids Res 13: 711-726, 1985

35. Wilkinson DS, Cihak A, Pitot HC: Inhibition of ribosomal ribonucleic acid maturation in rat liver by 5 -fluoroorotic acid resulting in the selective labeling of cytoplasmic messenger ribonucleic acid. J Biol Chem 246-6418-6427, 1971

36. Mohrenweiser HW, Pitot HC: Studies on the mechanism of 5-fluoroorotic acid inhibition of serine dehydratase induction. Arch Biochem Biophys 164: 663-668, 1974

37. Old SE, Mohrenweiser HW: Nucleotide sequence of the triosephosphate isomerase gene from Macaca mulatta. Nucl Acids Res 16: 9055, 1988

38. Marie J, Simon MP, Dreyfus JC, Kahn A: One gene, but two messenger RNAs encode liver $\mathrm{L}$ and red cell L'pyruvate kinase subunits. Nature 292: 70-72, 1981

39. Penhoet E, Rajkumar TS, Rutter WJ: Multiple forms of fructose diphosphate aldolase in mammalian tissues. Proc Natl Acad Sci USA 56: 1275-1282, 1966

40. Whitt GS: Genetics, developmental and evolutionary aspects of the lactate dehydrogenase isozyme system. Cell Biochem Funct 2: 134-139, 1984

41. Law ML, Kao FT: Regional assignment on human chromosome 12 of seven genes TPI-1, TPI-2, GAPD, LDHB, ENO2, SHMT, PEPB. Cytogenet Cell Genet 25: 179-180, 1979

42. Prescott DM: Control of the initiation of DNA synthesis in mammalian cells. Ann NY Acad Sci 397: 101-109, 1982

43. Gillis S, Crabtree GR, Smith KA: Glucocorticoid-induced inhibition of T-cell growth factor production I. The effect on mitogen-induced lymphocyte proliferation. J Immunol 123: $1624-1631,1979$

44. Calabretta B, Kaczmarek L, Mars W, Ochoa D, Gibson CW, Hirschhorn RR, Baserga R: Cell-cycle-specific genes differentially expressed in human leukemias. Proc Natl Acad Sci USA 82: 4463-4467, 1985

45. Friedman RL, Manly SP, McMahon M, Kerr IM, Stark GR: Transcriptional and posttranscriptional regulation of interferon-induced gene expression in human cells. Cell 38: $745-755,1984$
46. Denhardt DT, Edwards DR, Parfett CLJ: Gene expression during the mammalian cell cycle. Biochem Biophys Acta 865: 83-125, 1986

47. Decker RS: Structure and genetic relationships of human triosephosphate isomerase isozymes. Ph.D. Thesis University of Michigan 1982

48. Old SE: Primate triosephosphate isomerase isozymes and gene structure. Ph. D. Thesis University of Michigan 1987

49. Nadal-Ginard B, Gallego ME, Andreadis A: Alternative splicing: Mechanistic and biological implications of generating multiple proteins from a single gene. In: Genetic Engineering: Principles and Methods Vol. 9: 249-280, J.K. Setlow ed. Brookhaven National Laboratory. Lipton, New York, 1987

50. Hagenbuchle O, Tosi M, Schibler U, Bovey R, Wellauer PK, Young RA: Mouse liver and salivary gland a-amylase mRNAs differ only in $5 \%$ non-translated sequences. Nature 289: 643-646, 1981

51. Ruiz-Opazo N, Weinberger J, Nadal-Ginard B: Comparison of a-tropomyosin sequences from smooth and striated muscle. Nature 315: 67-70, 1985

52. Young RA, Hagenbuchle $O$, Schibler U: A single mouse a-amylase gene specifies two different tissue-specific mRNAs. Cell 23: 451-458, 1981

53. Zardi L, Carnemolla B, Siri A, Petersen TE, Paolella G, Sebastio G, Baralle FE: Transformed human cells produce a new fibronectin isoform by preferential alternative splicing of a previously unobserved exon. EMBO J 6: 23372342,1987

54. Ikuta $T$, Yoshida A: mRNA for the three human alcohol dehydrogenase subunits: size heterogeneity and developmental changes. Biochem Biophys Res Comm 140: 10201027,1986

55. Medford RM, Nguyen HT, Destree AT, Summers E, Nadal-Ginard B: A novel mechanism of alternative RNA splicing for the developmentally regulated generation of troponin $T$ isoforms from a single gene. Cell 38: 409-421, 1984

56. Noguchi $T$, Inoue $H$, Tanaka $T$ : The $m_{1}$ - and $m_{2}$-type isozymes of rat pyruvate kinase are produced from the same gene by alternative RNA splicing. J Biol Chem 261: 1380713812, 1986

57. Rowan RG, Brennan MD, Dickinson WJ: Developmentally regulated RNA transcripts coding for alcohol dehydrogenase in Drosophila affinidisjuncta. Genetics 114: 405-433, 1986

58. Straus D, Gilbert W: Chicken triosephosphate isomerase complements an Escherichia coli deficiency. Proc Natl Acad Sci USA 82: 2014-2018, 1985

Address for offprints:

H. Mohrenweiser,

Biomedical Sciences Division L-452,

Lawrence Livermore National Laboratory,

Livermore, CA 94550, USA 